CESIS Electronic Working Paper Series

Paper No. 333

\title{
My Urban Idol 2050 - The City of Gothenburg
}

\author{
Charlie Karlsson
}

November, 2013 


\title{
My Urban Idol 2050 - The City of Gothenburg
}

\author{
By Charlie Karlsson ${ }^{1}$
}

\begin{abstract}
I have been asked to write a paper over "my urban idol 2050" to be the foundation for a presentation at a session at the ERSA congress in Bratislava in August 2012. No special instructions were given, so I have chosen to write a kind of scenario for the possible future development in the region where I live - the Gothenburg region. I have not used a traditional scenario technique with several different scenarios. Instead I present one scenario, which I have developed based upon some of the information I have about the region, ideas found in the literature in the field and ideas developed by the SWECO team during the RiverCity workshop in June 2011. Certainly none of us know what the future will bring but I hope that at least my attempt will stimulate some thinking and some discussions about urban development both in general and in Gothenburg.
\end{abstract}

Key-words: Urban development, scenario, urban region, urban planning, new tradeable sectors, key occupations, investments, built environment, city branding, climate change, creativity

JEL Codes: H40, H70, I30, J20, O18, R11, R58

\footnotetext{
${ }^{1}$ Jönköping International Business School \& Blekinge Institute of Technology Charlie.karlsson@jibs.hj.se
} 


\section{INTRODUCTION}

I have been asked to write a paper over "my urban idol 2050" to be the foundation for a presentation at a session at the ERSA congress in Bratislava in August 2012. No special instructions were given, so I have chosen to write a kind of scenario for the possible future development in the region where I live - the Gothenburg region. I have not used a traditional scenario technique with several different scenarios. Instead I present one scenario, which I have developed based upon some of the information I have about the region, ideas found in the literature in the field and ideas developed by the SWECO team during the RiverCity workshop in June $2011 .^{2}$ Certainly none of us know what the future will bring but I hope that at least my attempt will stimulate some thinking and some discussions.

\section{BACKGROUND}

The city of Gothenburg was founded in 1621 by the Swedish king Gustavus Adolphus in the middle of a struggle for land and commerce, not least with Denmark, who at that time controlled most of the Southern and South-Western parts of today's Sweden. Gothenburg had a strategic location close to the mouth of the river Göta Älv suitable to protect the Swedish interests in the West and was from the beginning built as a fortress town. Special benefits were introduced to attract people to settle in the newly created town. Many of the new settlers came from abroad, and when the original mounds and moats were constructed German, Dutch and English was spoken alongside Swedish.

The fortress town was soon transformed into a centre of commerce, in particular in terms of exports and imports. Demolishment of the mounds began in the early 1800s and commerce and the shipping industry expanded. The number of inhabitants increased considerably during the $18^{\text {th }}$ and the $19^{\text {th }}$ centuries. Between 1870 and 1914 Gothenburg was the main emigration port for the more than one million Swedes that left Sweden mainly for the US.

During the second half of the $19^{\text {th }}$ century the mechanical and textile industries started to grow in Gothenburg and this gave way to a larger industrial expansion in the early decades of the $20^{\text {th }}$ century not least in the form of large shipyards. Between 1945 and the first oil crisis in the early 1970s the city experienced a rapid growth in the manufacturing sector, the public sector and the construction sector. There was a substantial migration into the city from Southern Europe, Finland and from the rest of Sweden, which made it necessary to engage not least in large scale housing construction to provide housing for an expanding population.

The first oil crisis created an industrial crisis in Gothenburg affecting in particular the shipping industry and the three large shipyards with their many suppliers in the region. The economic activities declined and unemployment increased substantially. However, in the 1980s the economy in the city started to grow again, spurred not least be the success of many of the multinational firms, such as Volvo, Ericson, SKF and

\footnotetext{
${ }^{2}$ I thank the other members of the SWECO team for being able to use here some of the ideas developed by the team during the workshop.
} 
Astra (later Astra-Zeneca), with substantial operations in the region. Also the business service sector started to grow but it did not develop to the same extent as the business service sector in the two other metropolitan regions in Sweden - Stockholm and Malmö. In the business service sector it was in particular the logistics sector that developed strength serving the shipping industry in the region and the activities in the harbour of Gothenburg - the largest harbour in the Nordic countries. However, having a big harbour was not enough to make Gothenburg a real competitor with the capital Stockholm in terms of exports and imports as illustrated in Table 1.1. This was in particular true for the retail and wholesale industries.

Table 1.1 Shares of Sweden's exports and imports in 2004 (per cent)

\begin{tabular}{|l|c|c|c|c|}
\hline & $\begin{array}{c}\text { Exports from } \\
\text { retail and } \\
\text { wholesale in- } \\
\text { dustries }\end{array}$ & $\begin{array}{c}\text { Exports from } \\
\text { manufacturing } \\
\text { industry }\end{array}$ & $\begin{array}{c}\text { Imports to } \\
\text { retail and } \\
\text { wholesale in- } \\
\text { dustries }\end{array}$ & $\begin{array}{c}\text { Imports to } \\
\text { manufacturing } \\
\text { industry }\end{array}$ \\
\hline Stockholm & 51 & 26 & 57 & 21 \\
\hline Gothenburg & 14 & 18 & 13 & 20 \\
\hline
\end{tabular}

Source: Johansson, et al., (2010)

During the same period the two universities in Gothenburg - University of Gothenburg and Chalmers Institute of Technology - expanded substantially both in terms of students and R\&D funding, increasingly cooperating with industry in the region. Also the Gothenburg airport expanded substantially offering more and more direct connections to important cities in Europe. The city also benefitted from a very active city and region management not least quite successfully marketing Gothenburg as an event city. However, overall the development of the city (= municipality) of Gothenburg was limited by its market potential that in 2005 was only 64.4 per cent of that of the city of Stockholm. Similarly the accessibility to work places within in the city in 2005 for inhabitants in the city of Gothenburg was only 64.5 per cent of that for inhabitants in the city of Stockholm. The accessibility to workplaces in the rest of the region for inhabitants in the city of Gothenburg was only 61.9 per cent of that for inhabitants in the city of Stockholm. However, the city of Gothenburg was a major provider of workplaces in the region. 58 per cent of the workplaces in the region was in 2006 located in the city of Gothenburg, which can be compared with 47 per cent of the workplaces in the Stockholm region located in the city of Stockholm. Thus, what happened in the city of Gothenburg was of major importance for the whole Gothenburg region.

In 2005, the Gothenburg region consisting of 19 municipalities had a population of a little more than one million equal to $11.2 \%$ of the total population in Sweden. In 1950 the region had $10.1 \%$ of Sweden's population. This was the result of a population increase of $61.3 \%$ during the period 1950-2005. Between 1970 and 2005 the population increased with 205,000 people, which was equal with $21.2 \%$ the whole population increase in Sweden. The region accounted for $11.9 \%$ of the total wage sum in Sweden in 2006 and was the region that increased its wage sum share fastest of all regions in Sweden between 1999 and 2006.

In terms of growth of wage sum between 1990 and 2007 the Gothenburg region was on par with the Stockholm region, 57 and $58 \%$, respectively. However, the distribution of this growth over sectors was very different, which is illustrated by Table 1.2. 
While the wage growth in the Stockholm region was concentrated to private firms and private service firms, the wage growth in the Gothenburg region a concentrated to the public sector and manufacturing firms. The employment share for business services was in 2006 substantially lower in the Gothenburg region (32\%) than in the Stockholm region (42\%). In 2006, the Gothenburg region almost totally missed any industries within financial services and business services with a high or very high specialisation. Industries with high or very high specialization was in the Gothenburg region mainly found within manufacturing and trade. New firm formation per 10,000 inhabitants during the period 1993-2004 was substantially lower in the Gothenburg region $(65 \%)$ than in the Stockholm region $(85 \%)$. The largest difference was for advanced services.

Table 1.2 Growth of wage sum between 1990 and 2007 in the Stockholm region and the Gothenburg region (per cent)

\begin{tabular}{|l|r|r|r|r|}
\hline \multicolumn{1}{|c|}{ Region } & Private firms & $\begin{array}{c}\text { Private service } \\
\text { firms }\end{array}$ & Public sector & $\begin{array}{c}\text { Manufacturing } \\
\text { firms }\end{array}$ \\
\hline Stockholm & 78 & 101 & 17 & 21 \\
\hline Gothenburg & 64 & 86 & 40 & 47 \\
\hline
\end{tabular}

Source: Johansson, et al., (2010)

A special problem in the Gothenburg region in this period was the low knowledge intensity (=share of employees with a university education of three years or more), which was substantially lower than in the Stockholm region (Table 1.3). Interestingly, this was in particular the case in the manufacturing industry, which as we saw above was a speciality of the Gothenburg region. Overall, the concentration of knowledge and $R \& D$ resources is substantially lower in the Gothenburg region than in the Stockholm region (see Table 1.4)

Table 1.3 Knowledge intensity, i.e. share of the employees with a long university education (three years or more) (per cent)

\begin{tabular}{|l|r|r|r|}
\hline \multicolumn{1}{|c|}{ Region } & The private sector & $\begin{array}{c}\text { Manufacturing } \\
\text { industry }\end{array}$ & Advanced services \\
\hline Stockholm & 28.1 & 25.2 & 38.2 \\
\hline Gothenburg & 24.1 & 19.9 & 36.9 \\
\hline
\end{tabular}

Source: Johansson, et al., (2010)

Table 1.4 The concentration of knowledge and R\&D resources, 1993-1999 (percent)

\begin{tabular}{|l|r|r|r|}
\hline \multicolumn{1}{|c|}{ Region } & $\begin{array}{c}\text { Knowledge-inten- } \\
\text { sive labour }\end{array}$ & $\begin{array}{c}R \& D \text { in companies } \\
\text { (man-years) }\end{array}$ & $\begin{array}{c}\text { University } R \& D \\
\text { (man-years) }\end{array}$ \\
\hline Stockholm & 38.3 & 42.1 & 45.8 \\
\hline Gothenburg & 11.3 & 21.8 & 17.8 \\
\hline
\end{tabular}

Source: Gråsjö (2006) 
Despite a substantial recovery during the three decades after the crisis in the 1970s it was in the early 2010s obvious for the politicians in the city of Gothenburg and the Gothenburg region that the future offered a large number of challenges that needed to be met with a battery of urban development policies. The challenges that faced the politicians are presented in the next section.

\section{MAIN CHALLENGES OF GOTHENBURG REGION IN THE EARLY 2010s}

The challenges facing the politicians in the City of Gothenburg and the Gothenburg region at the early 2010s were identified in a number of studies by researchers at the University of Gothenburg and Chalmers Institute of Technology. The foundations for these studies were the convictions

- that cities are engines of economic growth and social development,

- that cities provide economies of scale and agglomeration,

- that cities have sustained industrial and commercial development everywhere including Sweden (Dogan \& Kasarda, 1988),

- that cities serve a primary function as the locations where new forms of economic activities and economic organisations evolve and gain higher value,

- that cities supply the economic, cultural and social infrastructure within which many businesses and entrepreneurial acts are incubated and natured, and

- that cities to an increasing degree are also the key-nodes of capital accumulation, investments in new sectors, and focal points of the development of specialised services (Daniels, 2004).

The studies were also based upon the observations

- that as service jobs have become increasingly important, the importance of cities in economic performance is strengthened (Castells, 1989; Daniels, 1993; Bryson, Daniels \& Warf, 2004),

- that both industrial and service activities, along with new services related to banking, finance, media, and communication, constitute the new economic base of cities (Sassen, 1994),

- that with globalization, competition between cities had intensified, and

- that cities increasingly battle with each other to attract international investments (Sassen, 2002).

Naturally, these studies had their limitations since the understanding at this time of the processes of change that affect cities and urban regions was insufficient and the theories subject to dispute despite centuries of scholarship and research focused on the nature of cities (Mumford, 1961), the metropolitan experience (Harvey, 1989) and the dynamics of regions (Karlsson, et al., 2009). This 'knowledge gap' was a reflection both of the complexity of cities as locations of multifarious interdependent processes and the fundamental difficulty of generating relatively enduring explanations of ever changing forms of social and economic behaviour and their spatial manifestations. However, even if there was a 'knowledge gap', the research could be based a substantial knowledge and understanding in fields, such as local economies (Blakely \& Bradshaw, 2002), innovation and entrepreneurship in urban regions (Karlsson, Jo- 
hansson \& Stough, 2009), urban housing markets (Burke \& Zakharov, 2006), and processes of urban politics (Judge, Stoker \& Wolman, 1995).

The main challenges identified were the following (in no particular order):

- Spatial organization, urban morphology, sense of place, local character, civic differences, diversity, cultural variety, image, distinctiveness and design: how to ensure that the city and the region and their different neighbourhoods are good places to live and work, that they are designed to maximize the chances and benefits of positive urban encounters, creativity, innovation, entrepreneurship and economic performance, and that they inspire the inhabitants in their daily lives as well as visitors?

- Health and wellbeing: how shall the city and the region support and promote the opportunities for healthy lifestyles and provide services and treatment for those ill-health who requires it considering that the population is ageing?

- Housing and accommodation: how shall the city and the region respond to the housing needs of an increasing population and to the aspirations of the citizens and what and how shall the city and the region provide for those including university students and "bohemians" who cannot afford to rely on market based provisions?

- Leisure, recreation, arts and culture: what shall the city and the region provide for the entertainment and the experiences of its citizens as well as its visitors and what shall be the balance between public and commercial provision ${ }^{3}$

- Social and welfare services: how shall the city and the region provide social services to people that need them without stigmatizing the recipients and taxing too heavily the majority that pay taxes to pay their costs and how can individuals, groups and communities be supported in meeting their own needs?

- Jobs, social inclusion and incomes: how shall the city and the region ensure that opportunities to enjoy reasonable secure and well-paid jobs is available to all who want it and that local firms and public sector units are able to recruit and retain suitable skilled employees?

- Education and research: how shall the city and the region make certain that the education capacity and quality matches the demand of the future and that the public research capacity and quality makes it possible for the region and its businesses to compete efficiently in the knowledge-based world economy? ${ }^{4}$

- Globalization and multinational firms: what role can Gothenburg play in the global system and how can the region attract multinational firms in competition with urban and metropolitan regions around the world?

- Mobility, connections, transport, communications and infrastructure: how shall the city and the region ensure that citizens and economic agents can communicate effectively within the region as well as with other regions, that citizens can travel between different parts of the region as well as to other re-

\footnotetext{
${ }^{3}$ One particular challenge in the field of culture was how to get the Gothenburg Opera and the Gothenburg city theatre up to a high international standard, i.e. to a world class.

${ }^{4}$ It was very clear the even if several education programs and the research at many departments at Gothenburg University and Chalmers Institute of Technology was of high international standard there were education programs and also research at some departments characterized by low quality.
} 
gions at reasonable costs (financial and time), and that freight transports in the region not least to and from the harbour can flow efficiently? ${ }^{5}$

- Crime and community safety: how can the city and the region ensure that every citizen and visitor to the region feel relatively free to live, work, move and enjoy life without threat to themselves or their property?

- Financing: how can the city and the region ensure that public investments, public consumption and public transfers are financed without taxing the citizens to heavily and raising service fees to unacceptable levels?

- Climate change: how shall the city and the region ensure that climate neutrality is achieved and that the threat of a raising see level is met?

- Democracy, governance and efficiency: how can the city and the region in face of the immanent challenges speed up political decision making and still preserve the democratic rights of the citizens?

Although the challenges listed above were approached and better understood through rigorous analytical research, their solution depended upon that additional political challenges were meet in a proper manner. One basic political challenge was that the decision-making powers of the national state had shifted upward to the supra-national and international level and downward to regional and local authorities but also from government to non-governmental bodies in the face of changing technologies and a globalizing economy (Brenner, 2004). Thus, it was clear to the policy-makers in the City of Gothenburg and the Gothenburg region that if the challenges should be met they had to act themselves and not wait for the national government in Stockholm or the EU to act.

It was in the early 2010s obvious that the facts did not speak for themselves and that political solutions did not emerge magically from empirical analyses, even if they were of high quality. Political problems had to be solved and it was critical how the challenges were framed, how the solutions were conceived and how the implementation was pursued. Certainly, certain issues, so called 'wicked issues' (Rittel and Webber, 1973), were inherently more complex to solve than others. It turned out to be difficult to agree on a definition and framing of the different challenges including how they might be solved and even how success should be defined. To deal with the 'wicked issues' a cognitive approach to policy-making was taken focusing on how decision-makers' beliefs, attitudes and preferences affect their decisions. The approach was based on Vicker's (1965) theory on the appreciative system that was developed to understand the mental process of decision-making. He stressed that it is important to understand the way in which a decision-maker constructs reality, on the one hand, and values, on the other. The process of realty judgement and of value judgement leads to action judgement or, in other words, to a concrete idea about the nature or direction of policies to be taken. The "appreciative system" of decisionmakers are made up by these three aspects of judgement (Vickers, 1965; Parsons, 1995) and was successfully applied to reduce the problem with 'wicked issues' in the City of Gothenburg and the Gothenburg region during the 2010s.

Given the enormity of the challenges facing the city of Gothenburg and the Gothenburg region in the early 2010s it became quickly obvious that there was a strong need

\footnotetext{
${ }^{5}$ One critical challenge was to create a greater understanding among the politicians in power in the City of Gothenburg of important role of the car for the development of and life in urban regions.
} 
of securing greater input from an active citizenry whilst clarifying the leadership responsibilities of those properly elected by due processes. The so called 'Gothenburg solution' that emerged combined in a creative way greater inclusivity and civic engagement in planning and governance with firm leadership, a strong government, in particular, in the implementation processes and a robust central planning for the city and the region. The approach chosen was motivated by the unprecedented degree of complexity in policy-making that had emerged in recent decades (Giddens, 1990; Beck, 1992; Karlsson, Johansson \& Stough, 2010) and implied that not only intergovernmental cooperation but also the active involvement of non-governmental actors with relevant resources (such as knowledge, delivery systems and legitimacy) were heavily involved in dealing with the many challenges faced.

New methods were developed and applied for encouraging active citizenship in order to include a large number of local residents in the broad processes of planning for the future. Firstly, the new methods involved a regional strategic partnership for the Gothenburg region as a whole and local strategic partnerships in each municipality in the region. These partnerships involved all relevant regional and local stakeholders, respectively, i.e. different public sector bodies and representatives of local businesses, local communities and interest groups. Each partnership prepared and regularly updated a vision and a strategy for promoting and improving the economic, social and environmental well-being of their area in a sustainable manner. That the partnership became a success was to a high extent the result of an active involvement of non-governmental actors (cf., Marks \& Hooghe, 2004) and not least the Chamber of Commerce in Gothenburg. Secondly, the new methods involved the creation of a representative citizens' panel for both the region and for each municipality in the region who were prepared to take part in regular surveys conducted by the region and the individual municipalities.

\section{THE WAY AHEAD}

A major problem for the city of Gothenburg and the Gothenburg Region in the early 2010s was the regional planning organization lacked authority. The Gothenburg region consisted of 19 independent municipalities, each with each own planning monopoly. The county of West Sweden to which the Gothenburg region belonged contained more than 50 municipalities and had only limited power to coordinate plans and activities in the Gothenburg region. In this situation the municipalities in the Gothenburg region gave a new authority to the regional planning organisation and let it take over the planning monopolies of the municipalities to the extent needed to guarantee a coordinated planning and implementation in the region. The politicians making up the regional planning council governing the regional planning organization were elected directly by the citizens in the region in general elections every fourth year.

During the years the regional planning council has launched a number of projects that has tried to address the challenges mentioned above. A basic proposition behind all these projects was that, by building upon existing and developing new unique strengths, original knowledge and creative capabilities, the City of Gothenburg and the Gothenburg region could build competitiveness on the basis of 'non-price' or quality-based advantages, rather than the costs or availability of localised resources. 
This basic proposition was based, in particular, upon the contributions by Porter (1990), Storper (1997), Leadbeater (1999), Florida (2004) and Karlsson, Johansson \& Stough (2011). The ambition was to create a high-value, high-skill, high-productivity urban economy with a capacity to raise living standards and the shield the citizens from low-cost competition in the new global economy.

This differentiation strategy implied an ambition to avoid direct price competition and instead to focus on improving the various capabilities of the city and the region to create and sustain the production of high-quality products and services and thus to promote prosperity. This included the creation of distinctive urban and non-urban environments to attract and retain skilled mobile workers - the creative class - as well as entrepreneurial firms with growth potential but also an avoidance of deregulation and special incentives to lure investments into the city and the region.

The theoretical argument for the differentiation strategy was that the city and the region should focus on increasing the range of positive economic externalities that improve the birth and the performance of firms by facilitating face-to-face contacts, information exchanges and the procurement of specialised skills, technological expertise, advanced knowledge-intensive business services and access to international transport and communications. Since the Gothenburg region was a small metropolitan region at the time, the differentiation strategy was based on a limited number of specialised industries and occupations creating products that could not be easily and rapidly copied because of the dynamic, cumulative character of local learning and innovation in the region but also on physical assets such as special cultural quarters, business incubators, science parks and residential districts. However, also intangible aspects was included in the strategy. Distinctive steps were taken to improve the reputation of the city overall but also to appeal potential migrants with particular lifestyles.

The choice of a differentiation strategy for the Gothenburg region was inspired by the literature on business strategy and in particular by the analysis of the sources of sustainable competitive advantage by Porter (1985 \& 1990) and his conclusion that "enduring competitive advantages in a global economy are often heavily localized, arising from concentrations of highly specialized skills and knowledge, institutions, rivalry, related business, and sophisticated customers" (Porter, 1998, 90). The reason for this choice is today rather easy to understand. In a business context, differentiation implies that firms offer something unique and not easily imitated that is valued extra by its customers. Thus, due to their distinctive capabilities they can sell their products at a premium price and earn excess profits, i.e. an economic rent (Kay, 1993). For firms differentiation may involve enhanced features, greater customer responsiveness and/or strong brand identities, which convey signals of higher quality, better utility, greater reliability and/or superior performance in some other respects (Grant, 2002). Intangible aspects may be important, where emotional, aesthetic and social considerations influence customer choices, as in the desires of economic agents for status, individuality and security. Differentiation through continuous adaptation, design improvements and brand reputation was in the early $21^{\text {st }}$ century widely advocated among researchers, consultants and policy makers in high-cost Western nations as the means for the firms in these nations to compete with emerging low-cost economic powers in Asia and elsewhere. 
When the differentiation strategy was made operational in the mid-2010's in particular four dimensions were focused: i) the development of new tradeable sectors, ii) an increase in the supply of key occupations, iii) investments in the built environment, and iv) the branding of the city of Gothenburg and the Gothenburg region.

\subsection{The development of new tradeable sectors}

The development of new tradeable sectors implied the identification and targeting of a limited number of emerging and existing 'industrial clusters' with growth potential where cluster firms and related organizations was assisted through concentrated efforts and mutual learning to develop unique strengths. The primary aim was to create a sufficient scale and density of activities with a range of sophisticated collaborators, material suppliers, higher education institutions and specialized knowledge-intensive business services (such as designers, investors, patent offices, suppliers of market intelligence, distributors, and financing specialists) to generate co-location economies. Much efforts were put into creating complex webs of intra- and inter-firm networks, where firms could learn, compete, compare and collaborate to ensure a self-reinforcing dynamism that could spur innovation and vitality, raise productivity, attract mobile capital and mobile skilled people, and thus generate growth from within and increase the attractiveness of the region.

A related aim was to stimulate original scientific research and to increase the technical expertise in specialised fields related to the cluster efforts and to strengthen the cluster firms' management competencies to adopt new advanced technologies. Special measures were taken to increase the opportunities for leading cluster firms to obtain tacit knowledge and best-practice technology through worker mobility, informal business relations and other information spillovers. The telecommunications infrastructure was gradually updated to be at world top level, the university research was expanded substantially, the Gothenburg airport got a high-speed rail connection from the city centre and was extended to also accommodate intercontinental flights and increased cargo transports by air. To accelerate the flow of knowledge from the universities to business, scientists have been encouraged to start their own firms and specialised incubators and venture capital institutions created to support business spinouts.

Interestingly, the most successful cluster in the Gothenburg region has been the auto cluster. In the mid-2010's Volvo Car was owned by the Chinese company Geely and in the early 2020's Volvo Trucks was bought by another Chinese company - Oldman. Even if the owners over the years have invested in several Volvo factories in China and the rest of Asia, they both have decided that Gothenburg shall be their major knowledge hub. The number of engineers in the two companies working with research, construction and design in Gothenburg is now in 2050 eight times larger than it was in 2010. Also Chalmers Institute of Technology has benefitted substantially from research funding for auto related research from the two Chinese companies and has now a new Chinese-financed campus close to auto factories with 2000 researchers and 5000 students.

\subsection{Increasing the supply of key occupations}

The focus on increasing the supply of key occupations reflected the changing view in the early 2000's of the drivers of local urban development, with a greater stress placed 
on skilled and highly educated people (and their networks) as the change agents and less emphasis on firms and industries (Andersson, 1985; Feser, 2003; Florida, 2004; Markusen, 2004; Karlsson, 2011). This shift in perspective at this time followed from the wider argument that intellectual resources (such as human intelligence, knowledge, creativity, skills and human capital) had become increasingly important inputs to economic growth at the expense of physical capital and natural resources (Johansson \& Karlsson, 2009). The growing emphasis on highly educated labour also reflected greater social and geographical mobility in the context of rising incomes, improved communications, outsourcing and off-shoring of selected functions and shortages of high-level skills and capabilities across expanding industries of the Western economies.

A first argument for targeting key occupations or advanced skill-sets for policy support was that they cut across many industries and was therefore more generic and versatile assets for promoting and sustaining economic development. Obvious examples at the time included software programmers, product designers, marketing and management specialists, engineers and research scientists. In principle, people with such skills could be readily employed in different industries, thereby increasing the regional economy's resilience and adaptability to changing internal and external conditions. The ambition was also to improve the diversity of the regional labour market to improve the opportunities for career choices and job progression. The hope was that there should be a useful cross-fertilization of ideas and techniques between industries in the region as a result of "knowledge workers" moving between firms in the same and in different industries, thereby enhancing overall productivity growth.

A second argument for targeting key occupations was that developing bundles of advanced skills, knowledge and abilities in the local labour pool could be a tool to increase the attractiveness of the Gothenburg region in a time when the competition between urban regions in the world was intensified. The underlying idea, which was launched by leading researchers in the late $20^{\text {th }}$ and early $21^{\text {st }}$ century (Stoper, 1997; Gordon \& Turok, 2005), was that an urban labour market thick in diverse competencies is important for firms in an era of flexibility, since firms during such an era are leaner and less self-reliant and therefore need to procure specialised competencies externally. The motivation was that when the dependence of firms on their local labour market increase this would benefit urban regions with a larger pool of advanced skills, especially when there is a reasonable fluidity within the pool and it is replenished with a steady stream of suitable incomers and locals entering the regional work force. It was observed that there was an additional advantage from investing in the aptitudes, amenities and environments required by key workers in that they then are less likely as a group to leave the region compared to individual firms, of which many tend to be more foot-loose. There was also an equity issue raised in the sense that skills programmes carefully matched with relevant occupations could help unemployed people in the region to compete more effectively for emerging job opportunities.

The third argument for targeting occupations was the case made in the late $20^{\text {th }}$ and early $21^{\text {st }}$ century that selected occupations involved in the arts and cultural activities enhance the attractiveness of places for other professionals and for knowledge-intensive firms by stimulating their creativity and thereby boosting economic growth. The basic motivation was that writers, musicians, actors, artists and other 'bohemians' are 
supposed to engender the cultural diversity, new forms of entertainment and tolerant social environments, which implies desirable life styles, enriching experiences and abundant opportunities for social interaction that in turn entice and anchor creative talent, young graduates, entrepreneurs and other energetic and innovative people and not least their employers. It was in particular the elaboration of this argument by Florida (2004) that encouraged the policy-makers in the Gothenburg region to shift their focus from creating a favourable 'business climate' for attracting firms and new industries to developing an attractive 'people climate'. In his book he had asserted that businesses increasingly follow the residential preferences of creative people rather than the reverse. In practical terms he put emphasis on 'liveability' and residential choices characterized by vibrant cultural amenities, original and authentic experiences, exciting outdoor pursuits, and an open and inclusive social milieu for talented people from diverse backgrounds to express their individual identities and thereby cultivate and develop their creative potential. He argued, for example, that the most prosperous US cities were also the most cosmopolitan, tolerant, open to new ideas and immigrants and effective at nurturing talent and mobilising creativity.

The policy-makers in the Gothenburg region found a fourth argument for focusing on developing occupations in Markusen (2004). She claimed that analysing and working with occupations improve the ability of public agencies to identify and support entrepreneurship because of the closer understanding gained of the needs and circumstances of particular groups of people. The field of arts and culture was launched as a good example since there are low barriers to entry and plentiful opportunities for selfemployment for people with natural talent and ingenuity but few formal qualifications. They have a potential to progress from serving the local market to export their music, artwork, writing, films and other creative content to other urban regions also in other countries. In that process they provide work for local agents, publishers, distributors and other business services. It was also argued that the career advancement may be relatively rapid for such groups to reach their potential, since the hierarchies are less structured than in most professions. Furthermore, some types of cultural activities and related training schemes could also be readily skewed towards deprived groups and neighbourhoods to promote social inclusion. It was also observed that artists and writers was attracted to less prosperous parts of the region because of the lower cost of accommodation to live and work.

A general motivation for targeting occupations was that strategies to develop distinctiveness through key occupations was seen as helpful in redressing the balance between urban policies aimed at people and at firms. Such strategies gave due recognition to the importance of the quality of the Gothenburg region as a place to live and work, and the role of broad-based education and training in regional economic development. A better understanding of the role of occupations was also thought to facilitate policies to address the segmented nature of the regional labour market and the obstacles to recruitment and upward mobility facing some groups of workers, not least those with a foreign background. The traditional initiatives had tended to focus on graduates and professionals but now it was more clearly understood that similar measures could be extended to address the challenges facing other groups, such as displaced manual workers adapting to structural changes.

\subsection{Investments in the built environment}


The built environment had been an important local and regional policy object in the Gothenburg region in the period after WWII, reflecting the significance of buildings and infrastructures in accommodating urban growth and ensuring the effectiveness of everyday flows of information, people, services and goods. Property was seen as a key issue in firm performance and firm location decisions. The quality of residential areas and related transport and leisure facilities was also seen as vital in household decisions to move to and to stay in the region and the satisfaction of urban living in the Gothenburg region. There were substantial challenges facing the decision makers in the Gothenburg region due to the partly old and congested transport infrastructure and lack of enough rental housing. The city of Gothenburg owned substantial shares of the land accessible for development in the city but development was retarded due to a substantial uncertainty among the policy makers of how to use the available land for development. There were numerous conflicts around development because of the diverse interests of various stakeholders as well as intense competition for land in the more densely developed areas in the city. At the same time there was a substantial awareness among policy makers in the region that without continuing investment in property renewal and redevelopment, the urban fabric was liable to deteriorate relative other urban regions of similar size.

It was well understood in the Gothenburg region in the early $21^{\text {st }}$ century that the built environment is a potent means of differentiation between urban regions given its obvious contribution to their character and sense of place. It was also clear to the policymakers at this time that there was economic aspects coupled to the built environment given its potential to generate positive as well as negative externalities deriving from particular buildings or districts and the effect they have on the value of surrounding buildings and districts. The preservation and restoration of unique historical buildings to preserve an impressive architectural legacy was given a high priority. It was also well understood that it was important to rehabilitate disused parts of the port, run-down parts of the waterfront and industrial warehouses and estates to create new 'flagship' developments but also to create attractive parks and public squares. Different initiatives have been taken during the years with different purposes and users, including visitors, external investors, local firms and existing and potential residents.

It became more and more clear for policy makers in the Gothenburg region in the second decade of the $21^{\text {st }}$ century that landmark buildings is a critical tool for promoting distinctiveness and that iconic structures are powerful statements in themselves to highlight something new that may act as catalysts to further investment in the vicinity by altering perceptions of the urban region through demonstration effects. The policy makers also saw it as a clear advantage that such buildings can accommodate unique cultural facilities such as museums and art galleries as well as venues for music and theatrical performances that could enhance of the Gothenburg region as a region to visit and to explore. It was also well understood among the policy makers that the public realm was just as important for conveying the quality of the region to tourists, residents and entrepreneurs. Convivial public spaces and attractive physical surroundings was seen as contributing to the urban experience, especially when supported by a modern transport system that connected different parts of the region efficiently, including the central business district, cultural and entertainment quarters, the residential areas, the airports and other transport nodes. 
In the late $20^{\text {th }}$ and early $21^{\text {st }}$ century greater policy emphasis was devoted to improving the physical fabric in the Gothenburg region by raising the quality of urban design, promoting higher density living in mixed-use neighbourhoods and reclaiming vacant and derelict land. Initiatives were taken to enhance the general standards of street and park cleanliness, personal safety and open space with less noise, crime, pollution and traffic congestion. This was part of a 'regional renaissance' agenda aimed at accommodating household growth, limiting suburban growth, protecting the countryside from development pressures and attracting people back to live, work and spend their leisure time in the city centre.

Most regional and local authorities and property developers in the Gothenburg region in the first decades of the $21^{\text {st }}$ century embraced these themes with enthusiasm. Since the early $21^{\text {st }}$ century the core of the Gothenburg region has experienced a substantial development of modern flats and successful conversions of older buildings into fashionable apartments. The policies focused on attracting and retain a new cohort of middle- and upper-income households and young professionals - the 'creative class' who preferred to live close to workplaces and amenities and accepted higher densities without gardens to care for. The enticing images that the Gothenburg region tried to offer included glamorous lifestyles, stylish contemporary designs, open waterfronts vistas and proximity to a vibrant metropolitan centre with abundant amenities, coffee shops, designer clothes stores and good jobs.

The policy makers in the Gothenburg region were instrumental in the creation of the current high-speed rail network in Sweden, which connects Gothenburg with Stockholm (1 h $45 \mathrm{~min}$ ), Oslo (1 h $15 \mathrm{~min}$ ) and Copenhagen (1 h $15 \mathrm{~min}$ ). They took in 2015 the lead in a lobbying campaign directed not only to the Swedish government and business community but also to the Norwegian and Danish counterparts and the EU. The building of the network has been financed by money from the EU, the Nordic governments and Nordic banks.

\subsection{The branding of the Gothenburg region}

There was an increasing emphasis on the image and the identity of the Gothenburg region in the early $21^{\text {st }}$ century. This chimed with the growing importance attached to intangible and soft assets in regional economic competitiveness. The use of a brand in the regional strategy was seen among policy makers in the region as an important means of communicating essential features of the region. The brand was thought to convey a deeper set of values and perceptions associated with it (such as status and style) that increase the loyalty and confidence of residents, entrepreneurs and visitors. Furthermore, a strong overall region brand was supposed to lend some coherence to arrange of otherwise loosely related attributes and help to subsume particular regional difficulties. It was thought to influence people's perceptions by adding an intangible quality that could not be captured easily by other urban regions. By appealing to people's underlying emotions, aesthetic imagination and social values and aspirations, it was hoped that the region's position could be elevated in the eyes of tourists, investors and existing and potential residents. The underlying assumption was that a positive image signalled an attractive lifestyle and a secure business milieu that should simplify migration and location decisions. Researchers of the time claimed that a strong reputation lowered the assessed risks for decision makers and provided an implicit kind of insurance against failure (Buck, et al., 2002). They also stressed that reputa- 
tion was significant because many of a region's subjective qualities are difficult to ascertain prior to the decisions being made, as in the case for tourists seeking a rounded experience but unable to get full information in advance. A reputable image was thought to communicate a consistent quality experience, which short-circuits search processes and boost interest.

\subsection{The RiverCity project}

It was early on very clear that for the Gothenburg region to meet its challenges, it was necessary to improve the functioning of the City of Gothenburg and particularly the central parts of the city that makes up the centre of the region. In the middle of the 2010s the regional planning council together with the City of Gothenburg launched a large-scale project with the name RiverCity Gothenburg, which during the last four decades has fundamentally transformed the city. The background to the project was the following developments:

- almost all harbour activities had left the central city freeing, for example, the free harbour era for development,

- the through-traffic along the river in the city centre had been tunnelled freeing land on the southern river bank available for development,

- an old industrial area north of the river had become mature for development, and

- a logistical centre nearby the central railway station was relocated to a better location at the outskirts of the city.

When the RiverCity project was launched, the underlying policy document stressed the following aspects:

1. GOTHENBURG AS A REGIONAL DRIVER: First, Gothenburg shall be the driver for the whole Western Sweden regarding dynamic business development, services, and knowledge and creative ideas.

2. GOTHENBURG AS A CITY WITH AN AGEING POPULATION: The development of Gothenburg in coming decades will be strongly influenced by an ageing population. This makes it necessary to supply many tailor-made amenities for a large share of the elderly urban population but also to facilitate for elderly people to continue their life in a liveable and safe city environment.

3. GOTHENBURG AS A DIVERSE CITY: Gothenburg has over the past decades seen an influx of large flows of immigrants and this has induced a dramatic change in population composition, but also generated a possibility to take care of diversity in supply of food, music, and theatre and city life

4. GOTHENBURG AS A CITY WITH A RICH CULTURAL HERITAGE: Gothenburg has a long political and cultural history and shows fascinating signs from the past, so that an abundant cultural heritage is a landmark of Gothenburg, which creates unprecedented future opportunities.

5. GOTHENBURG AS A WINNER: Gothenburg is located along a river, with the anticipation of climate change and sea level rise, parts of Gothenburg may become vulnerable areas, so that the need for safety strategies is rapidly increasing in importance. On the other hand, in a global perspective, Gothenburg probably is a winner, comparing to other parts of the world. That is another reason for Gothenburg to grow. 
The purpose of the next section is to highlight the developments in Gothenburg since the mid-2010s with a focus on the achievements of the RiverCity project, and by doing that explain why Gothenburg is my idol city.

\section{MAIN FEATURES OF THE CITY OF GOTHENBURG IN 2050}

A main characteristic of the developments in Gothenburg during the last 40 years is that it has gone from a divided and segregated city to a connected city, which has promoted the liveability and the attractiveness of the city as a whole. The developments that have taken place have four main features and in 2050 the city of Gothenburg is connected, cohesive, climate-smart and creative.

\subsection{The connected Gothenburg}

Good connections and an integration between the different parts of the city was an essential goal of the RiverCity project. A flexible mixed use in a grip pattern structure is one of the most important qualities that has been achieved through the implementation of the project. The implementation has also acknowledged Gothenburg as a city of small districts, where each district has its own distinct and unique character but at the same time is connected to each other in an urban grid with a minimum of barriers.

A primary idea in the RiverCity project was to make the river through the city a unifying element instead of being a dividing barrier. This goal has been achieved by the construction of several low-level multi-purpose bridges over the river at strategic locations. These bridges can be opened when needed. Thus, they are no obstacle for vessels on the river and serve the citizens and the visitors to Gothenburg most of the time. Some of the old ferry shuttles over the river have been preserved as a complement.

Within the RiverCity project the importance of the central railway station in Gothenburg was acknowledged and it has over the years been developed to be the most important multi-modal interchange for commuting in Western Sweden with the majority of the workplaces and services in the city centre accessible by walking. 90 per cent of all important work places in the Gothenburg region are now accessible by public transport. This mission was to a great extent accomplished through the creation of a new central commuter train station and the replacement of the old Göta Älv bridge by a new bridge. The central railway station is Gothenburg is also a major hub in the new high-speed railway network in the Nordic countries connecting Gothenburg with Oslo, Stockholm and Malmö/Copenhagen. The high-speed link to Stockholm also connects the Gothenburg/Landvetter airport with the city centre.

The urban transit system has been developed with the tramway and light rail network as its basic network. Provisions have been made for additional links across the river and the network has been extended to cover also the central development areas along the river. A system of tangential links have been created forming an outer ring around the central city providing easy access to important destinations without having to pass the city centre. The Circle Line (see Figure 5.1) provides the backbone of the light railway network and has become a structuring element for the developments in the 
central city. Higher density residential, office and commercial developments have taken place within walking distance from the stops of the Circle Line. The light rail network has been supplemented by priority bus services with biogas busses to ensure optimal coverage. The stops of the Circle line is connected by a system of walkways and bikeways integrated with parks and the open space system.

In order to eliminate the barrier along the Northern river bank, the harbour railway has been relocated to a new alignment further north. The freeway, Lundbyleden, also at the Northern river bank connecting to the harbour has been adjusted accordingly where needed to reduce its negative impact on the connection between the Northern part of the city and the city centre.

In order to provide access to the quayside at Masthuggskajen at the Southern river bank, the terminal for the ferries to Denmark has been relocated to Majnabbe, closer to the river mouth. As a consequence, it has been possible to adjust the freeway Götaleden along the Southern river bank and reduce its negative effect as a barrier between the city and the Southern river bank. The terminal for the ferries to Kiel in Germany, Amsterdam in the Netherlands and Harwich in England at Majnabbe has been relocated to the outer harbour to create space for the ferries to Fredrikshamn and Copenhagen in Denmark and Oslo in Norway.

A permanent terminal for visiting cruise liners has been created at the Northern river bank at Keillers quay in the Lundby docks adjacent to a bridge providing easy access to the central city.

Mobility centres have been created at strategic locations in the region providing real time transit information, car sharing programs, car pools and ride share information, bike rentals and repair and other services related to sustainable transportation. The developments in the central city within the RiverCity project have been based upon a basic structure of small blocks with the effect that the street network contributes to a fine-meshed internal connectivity as well as with a high connectivity with surrounding areas. Today, the urban transit system facilitates connections to the central city and also in all other directions.

The Green Ring that has been developed during recent decades is a multi-purpose greenway with an open storm water system. It is a primary element of the open space network that is used on a year-around basis, providing various amenities, recreational sports opportunities and at the same time re-introducing nature to the sites. 


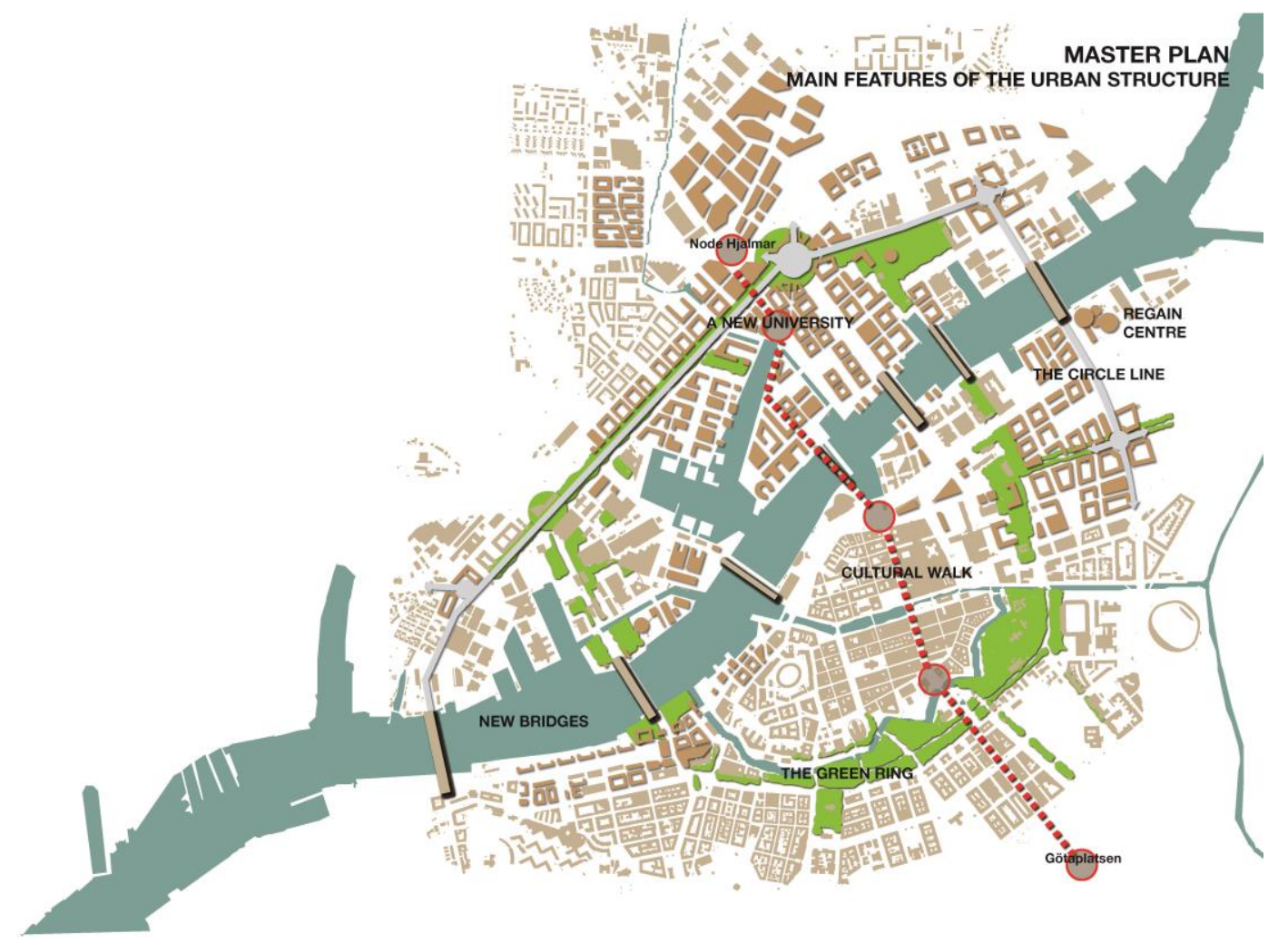

Figure 5.1 The RiverCity projecy area

Source: The SWECO team report from the RiverCity workshop in June 2011

An integral part of the public realm that has been created is the city-wide framework of green (parks and open green spaces) and blue (the river and the storm water ponds). The green and blue networks serve as contrasts to the grid pattern and the green serpentines throughout the central city with linkages to the courtyards in many blocks. The RiverCity parks have been designed as public and social spaces, closely connected with the built environment and easily accessible from every neighbourhood in the city. Thus, the open space structure is part of the mobility system in the city, with pleasant routes for walking and biking along, for example, the RiverCity Water Walks.

\subsection{The Climate-Smart Gothenburg}

Organic waste and municipal wastewater is used today to produce biogas, which implies that local bio-fuel is available for buses and cars. Climate-neutrality has been achieved through a combination of reduced demand and the introduction of energyefficient systems. Passive and plus-energy buildings, large-scale off-shore wind power, efficient solar panels, as well as block-level heating and cooling systems have developed side by side with the existing buildings and traditional solutions. The inhabitants have been encouraged to developed a responsible behaviour and are supported by interactive incentive and monitoring systems.

A vacuum waste collection system has been introduced in the city districts developed within the RiverCity project for the collection of combustible domestic waste and mixed light recyclables. The system has reduced the demand for heavy vehicles transport in these parts of the city. Food waste is collected separately and is anaerobi- 
cally digested to biogas and bio-fertilizer. Recycling of plant nutrients is a high priority in today's Gothenburg.

A new waste water system strictly for household sewage has been introduced in the "RiverCity districts". The plants for the treatment of sewages and food waste have been located inland close to agricultural areas in order to facilitate the reuse of purified bio-fertilizers (N, P, K and humus) for the production of food and biomass. Biofertilizers have today replaced chemical fertilizers for a part of the farmland in the region.

A Regain Centre has been created as a meeting point and activity centre inviting inhabitants to mend, reuse and increase their environmental awareness. The centre hosts exhibitions as well as commercial activities and a market place. Urban farming on roof-tops as well as in biospheres has added to improve local and global climate performance.

\subsection{The Cohesive Gothenburg}

One priority in the implementation of the RiverCity project has been to provide recreational opportunities, commercial, public and social services including schools, day care centres for children, health care and housing for elderly needing special services as well as good access to public transport. The design of buildings and the public realm has incorporated accessibility features to make neighbourhoods both "senior" and "children" friendly.

The city districts developed within the RiverCity project have contributed to make Gothenburg to a cohesive city that have a fine meshed mixed use structure with living, working and service functions in each block. These parts of the city are a truly mixeduse community with employment centres, commercial areas and private and public services interconnected with parks and open spaces. The distances between jobs, services and residencies have been substantially reduced. The multifunctional and composite urban form promotes walkability, which allows for increased human interaction while at the same time reducing the reliance on the private car.

High density mixed-use community cores have been developed and have become new focal points. They include a range of commercial uses (office/retail), higher density housing and public facilities including recreation centres.

Where possible a mixed-use block structure has created a pattern that accommodates and adjusts to different configurations depending on demand. Adaptability at the block level occurs through the successive development of mixed-use properties located within the boundaries of the main roadways and green/blue networks. Variation and flexibility have been promoted by distributing small parcels of large blocks among different developers generating social, economic and spatial diversity. The use of different block typologies has contributed to a versatile city landscape.

A guiding principle of the RiverCity project has been to assure diversity in the demographic structure. A rough pinpoint has been about a third of the population in each city district in ages -30, 30-60 and 60+, respectively. Demographic diversity in different housing areas has been achieved through a supply of dwellings in different sizes 
and different forms of tenure/ownership, which matches the changes over the life course of residents in terms of preferences and ability to pay. The variety in the supply of dwellings has been important not only to attract different kinds of households to each city district, but also to promote migration between dwellings within the same neighbourhood. Due to the demographic variety and the variety in the supply of dwellings in the developed districts in Gothenburg the running and development of schools, and other localised public and commercial services have improved substantially compared with the situation 40 years ago.

\subsection{The Creative Gothenburg}

For the year 2050, the European Union has designated the city of Gothenburg the title "The Creative Capital of Europe". The background to this honourable title is a number of strategic developments in the past four decades. Certainly, the most important developments have taken place within higher education and university research. In 2015 the University of Gothenburg was transformed from public ownership to became a foundation. At the same time the university was slimmed to contain only four faculties: humanities, social sciences, natural sciences and medicine. During the period 2015-2025, the Swedish government tripled the research funding for the university making it the major research university in Sweden. Interestingly, it was in particular research in the humanities that got a boost. The university's business school was transferred to a separate foundation giving it back the independence it had before 1969. The educations in the arts, design, culture, music and entertainment was gathered in a newly created college of creativity. Two professional schools was also created: a school of health sciences and a teacher training college (teachers for high schools are still trained at the University of Gothenburg). As a part of the RiverCity project a new graduate university with a focus on urban sustainability sciences was started. Linked to the new university a Nordic Sustainability Centre was established. Its purpose was to broaden community understanding about the importance of sustainable living and city building. Interactive exhibitions have over the years showcased the latest thinking and technologies related to sustainability. The centre also has developed a research facility for sustainable building and green technologies as well as a technology transfer centre for the commercialization of green technologies.

Besides the developments within higher education and research, the RiverCity project has worked with four strategic areas to make Gothenburg a more creative city: i) Gothenburg - the networked city, ii) Gothenburg - the liveable city, iii) Gothenburg the entrepreneurial city, and iv) Gothenburg - the pioneer city. The image "the networked city" has referred to the fact that in an interlinked world, a city like Gothenburg can no longer be an economic island but have to seek its development opportunities in the development of advanced transportation infrastructures, smart logistical systems and accessible communication systems through which it becomes a node in the global system of cities. The image "the liveable city" has addressed the view that Gothenburg is not only an energy and resource consumer and hence an environmental polluter, but can - through smart environmental and energy initiatives - act as an engine for ecological building strategies, and become a climate neutral agent in the economy of the future and an attractive place to work and live. The image "the entrepreneurial city" has assumed that in the current and future competition, Gothenburg can only grow, if it is able to maximize its creative, innovative and entrepreneurial potential. The image "the pioneer city" has referred to the innovative melting pot 
character of Gothenburg with its high cultural diversity and fragmentation of lifestyles. This has prompted not only big challenges, but also offered great opportunities for smart and creative initiatives in Gothenburg, through which it has become a global pioneer.

The success of Gothenburg as a creative city is today obvious whatever indicators we use. Gothenburg is the region in Sweden with the largest number of scientific publication per researcher, that largest number of patent applications per inhabitant, the largest number of new export products per inhabitant, the largest frequency of new firm formation, etc. Gothenburg has also achieved a leading position in Sweden in terms of design, music, literature, the arts, film, etc. Creative people increasingly gather in Gothenburg today because it is here it happens. Gothenburg also has become the most popular place to study in Sweden. No other city get so many applications per study place in higher education. Of the eight Nobel prizes awarded Sweden scientists since 2012, seven has landed in Gothenburg.

\section{WHY IS GOTHENBURG MY URBAN IDOL IN 2050?}

Why is Gothenburg my urban idol in 2050? The main reason is that Gothenburg is a diverse, friendly and safe city that has kept its very special characteristic - humour. In no other region in Sweden do you hear so many good stories told. I can easily reach the different parts of the region and not least the archipelago. The different parts of the city and the region are today well connected and still they keep their special character. Each district has its own restaurants and eating out today also implies travelling through the city and the region to find the best restaurants. The quality of entertainment has improved substantially in recent decades. The opera in Gothenburg is today by experts ranked as one of the leading opera houses in Europe and the symphony orchestra is also very highly ranked. The city theatre has become the main theatre in Sweden outcompeting the theatres in Stockholm for the best actors and actresses. In a parallel process, many free and often experimenting theatre groups have flourished in different parts of the city. For young people making their own music there are plenty of scenes all across the city and the region.

Today I can feel that Gothenburg is really an international city. Partly this has to do with the fact that the Gothenburg region today has a population of more than 2 million. The number of tourists has increased substantially and walking the streets I hear so many different languages spoken. Today the workforce in Gothenburg is also very international. Wherever I go in shops, restaurants, cafés, bars, etc. I try to guess from which country the staff comes. The same is true in much of public services, such as healthcare, nursery schools, home for elderly, etc.

Also the business community in the Gothenburg region is very international. There are many Chinese, Indian and Russian entrepreneurs in the region, which are there to take advantage of the creative environment and the high international accessibility not least for freight transport.

Furthermore, what I appreciate with Gothenburg is that it is accessible. I can go to Stockholm, Oslo and Copenhagen by high-speed train and I can fly with direct flights to numerous destinations in Europe and also to major hubs in North America and 
Asia. What I in particular value is that the earlier ferry lines to Fredrikshamn in Denmark and Kiel in Germany, now have been complemented with ferry lines to Oslo, Copenhagen, Amsterdam and Harwich. The increased fees for freight transport on roads have increased the demand for ferry transport. In parallel it has become much more popular for people to travel with ferries not least due to the excellent food served at the ferry restaurants and the possibility of buying tax free liquor, wine and beer on the ferries.

However, there are many aspects of my urban idol that I don't appreciate and which provide future challenges to the city and the region. The city and the region are still segregated with Europeans Americans clustering in certain areas and people from other continents clustering in other areas with higher unemployment, lower educational achievements, worse health and much higher criminality. Drug abuse is still a major problem in many parts of the city.

Another challenge for the future is the regional transport system. The expansion of the transport infrastructure and the public transport system has not kept pace with the population growth in the city and the region. Despite the establishment of a regional planning authority and congestion fees for cars there has been a substantial urban sprawl. Due to local protests in central parts of the city it has been very difficult to build new housing close to existing housing in central locations. There has also been a very strong local resistance to the construction of high raise buildings. The lack of a metro system has become more and more obvious and there is a strong need for investments in such a system.

A third challenge that must be met is the rising sea level and the rising level of the Göta Älv river and other rivers in the region due to increasing levels of rain. Some investments have been made to deal with this but partial flooding is today a regular phenomenon, in particular in the autumns. Further investments in barriers is needed but have been delayed due to long discussions between the city, the region and the national government concerning who shall bear the burden of the financing.

A fourth challenge remaining is the so-called "Gothenburg spirit". The "Gothenburg spirit" stands for many things but in particular for a special manner of running the city. The city is still run as a conglomerate of public authorities and a large number of companies 100 per cent owned by the city. The leading politicians are normally sitting on many chairs since they are not only sitting in the city board but also in several company boards. It is often unclear where decisions are taken and the necessary control is missing. Regularly, different "affairs" are disclosed by the media but nothing happens in the political system, since that same parties as 40 years ago are in power. The Swedish law on the governance of municipalities give local politicians a high degree of freedom and in the Gothenburg case the necessary self-regulation and control has not worked. As long as the citizens re-elect the same parties to power nothing effective is done to this local corruption. So I doubt that it will change in the future.

So even if Gothenburg 2050 is my idol city, it is no perfect city. There are still many challenges to be met. 


\section{REFERENCES}

Andersson, Å.E. (1985), Kreativitet - Storstadens framtid, Prisma, Värnamo

Beck, U. (1992) Risk Society: Towards a New Modernity, Sage Publications, Newbury Park, CA

Blakely, E. \& T. Bradshaw (2002), Planning Local Economic Development: Theory and Practice, Sage, London

Brenner, N. (2004), New State Spaces: Urban Governance and the Rescaling of Statehood, Oxford University Press, Oxford

Bryson, J.R., P.W. Daniels \& B. Warf (2004), Service Worlds: People, Organizations, Technologies, Routledge, London

Buck, N., et al., (2002), Working Capital: Life and Labour in Contemporary London, Routledge, London

Burke, T. \& R. Zakharow (2006), Long Term Futures for Australia: Using 'Foresight' to Explore Alternative Visions and Choices, AHURI Research Policy Briefing, Issue 76, July

Castells, M. (1989), The Informational City, Blackwell, Oxford

Daniels, P.W. (1993), Service Industries in the World Economy, Blackwell, Oxford

Daniels, P.W. (2004), Urban Challenges: The Formal and Informal Economies in Mega-Cities, Cities 21, 501-511

Dogan, M. \& J.D. Kasarda (1988) (Eds.) The Metropolis Era, Vol. 1: A World of Giant Cities, and Vol. 2: Mega-Cities, Sage Publications, Beverly Hills, CA

Feser, E.J. (2003), What Regions Do rather than Make: A Proposed Set of Knowledge-Based Occupation Clusters, Urban Studies 40, 1937-1958

Florida, R. (2004), The Rise of the Creative Class, Basic Books, New York

Giddens, A. (1990), Consequences of Modernity, Stanford University Press, Stanford

Gordon, I. \& I. Turok (2005), How Urban Labour Markets Matter, In Buck, I., et al., (Eds.), Changing Cities, Palgrave, London, 242-264

Grant, R.M. (2002), Contemporary Strategy Analysis, Blackwell, Oxford

Gråsjö, U. (2006), Spatial Spillovers of Knowledge Production - An Accessibility Approach, JIBS Dissertation Series No. 034, Jönköping International Business School, Jönköping

Harvey, D. (1989), The Urban Experience, Blackwell, Oxford

Johansson, B., et al., (2010), Storstadsregionerna och ekonomins utveckling, JIBS Research Report Series No. 2010-1, Jönköping International Business School, Jönköping

Johansson, B. \& C. Karlsson (2009), Knowledge and Regional Development, in Capello, C. \& P. Nijkamp (Eds.), Handbook of Regional Growth and Development Theories, Edward Elgar, Cheltenham, 239-255

Judge, D., G. Stoker \& H. Wolman (Eds.), Theories of Urban Politics, Sage, London

Karlsson, C. (2011), Clusters, Networks and Creativity, in Andersson, D.E., Å.E. Andersson \& C. Mellander (Eds.), Handbook of Creative Cities, Edward Elgar, Cheltenham, 85-114

Karlsson, C., et al., (2009), Innovation, Dynamic Regions and Regional Dynamics, in Karlsson, C., et al., (Eds.), New Directions in Regional Economic Development, Springer, Berlin, 1-33

Karlsson, C., B. Johansson \& R.R. Stough (2009) (Eds.), Entrepreneurship and Innovation in Functional Regions, Edward Elgar, Cheltenham 
Karlsson, C., B. Johansson \& R.R. Stough (2010) (Eds.), Entrepreneurship and Regional Development. Local Processes and Global Patterns, Edward Elgar, Cheltenham

Karlsson, C., B. Johansson \& R.R. Stough (2011) (Eds.), Innovation, Technology and Knowledge, Routledge, London

Kay, J. (1993), Foundations of Corporate Success, Oxford University Press, Oxford

Leadbeater, C. (1999), Living on Thin Air, Penguin, London

Marks, G. \& L. Hooghe (2004), Contrasting Visions of Multi-Level Governance in Bache, I. \& M. Flinders (Eds.), Multi-Level Governance, Oxford University Press, Oxford, 15-30

Markusen, A. (2004), Targeting Occupations in Regional and Community Economic Development, Journal of the American Planning Association 70, 253-269

Mumford, L. (1961), The City in History: Its Origins, Its Transformations and Its Prospects, Penguin, London

Parsons, W. (1995), Public Policy. An Introduction to the Theory and Practice of Policy Analysis, Edward Elgar, Cheltenham

Porter, M.E. (1985), Competitive Advantage; Creating and Sustaining Superior Performance, Free Press, New York

Porter, M.E. (1990), The Competitive Advantages of Nations, Free Press, New York

Porter, M.E. (1998), On Competition, Harvard Business School Press, Cambridge, MA

Rittel, H. \& M. Webber (1973), Dilemmas in a General Theory of Planning, Policy Sciences 4, 155-169

Sassen, S. (1994), Cities in the World Economy, Pine Forge Press, Thousand Oaks, CA

Sassen, S. (2002), Locating Cities on Global Circuits, Environment and Urbanization $14,13-30$

Storper, M. (1997), The Regional World: Territorial Development in a Global Economy, Guildford Press, New York

Vickers, G. (1965), The Art of Judgement: A Study of Policy-Making, Chapman \& Hall, London 